\title{
Heat transfer analyses of natural fibre composites
}

\author{
H. Takagi ${ }^{1}$, A. N. Nakagaito ${ }^{1} \&$ K. Liu ${ }^{2}$ \\ ${ }^{1}$ University of Tokushima, Japan \\ ${ }^{2}$ Wuhan Textile University, China
}

\begin{abstract}
This paper reports a typical functional property of natural fibre reinforced polymer composites, also referred to as green composites, namely their transverse (along the thickness direction) thermal insulation. This functionality is mainly derived from the inherent internal morphology of the natural fibres. The thermal transfer property of polymer composites is one of the most important functional issues for material design in heat-related applications. Normally, the thermal conductivity of natural fibres is much lower than that of conventional mineral fibres such as glass and carbon fibres. Therefore a better thermal insulation performance is easily attained by mixing a matrix with natural fibres in polymer composites. In addition, the thermal properties of the natural fibre composites can be controlled not only by changing the thermal conductivity values of the matrix but also by changing the internal microstructure of the natural fibre.
\end{abstract}

Keywords: natural fibre composites, thermal conductivity, lumen, abaca, bamboo, unidirectional composites.

\section{Introduction}

In recent years, a great amount of research has been carried out on the development of environmentally friendly polymer composites, also known as green composites [1-10]. Many types of green composites have been proposed up to now; most of them have been composed of a biodegradable polymer and natural fibres. Therefore, this type of green composite exhibits a fullybiodegradable nature [1], thus its disposal problem is not serious and sometimes green composite waste after usage does not have to be taken care of, because it 
can be completely biodegraded by the action of microorganisms. Another advantage of green composites is that they can be made from yearly renewable resources, such as corn, potato and various plant fibres. So this type of bio-based green composites is regarded as a carbon neutral, renewable material.

Most studies on natural fibre composites have focused on their mechanical behaviour, because the natural fibre composites in the early stages of their development were considerably weaker than conventional structural composites; namely glass fibre-reinforced plastics (GFRP). Thus, researchers have tried to fabricate natural fibre composites using a wide variety of methods such as pressforming, injection moulding and filament winding. Due to such efforts, the mechanical performance improved to almost the same strength level as that of conventional composites and various moulding methods were established as well.

It is well known that the natural fibres have a unique microstructure that is called 'lumen'. This lumen is usually filled with air, thus the natural fibres have a tubular structure. This internal microstructure is the origin of unique functional properties of natural fibre composites. It has been reported that the thermal conductivity of poly lactic acid/bamboo green composites is smaller than those of GFRP and that the thermal conductivity of bamboo green composites is approximately equal to that of woods with the same density level [11]. Liu et al. $[12,13]$ reported the relationship between thermal conductivity of natural fibre composites and the size of lumen obtained both experimentally and theoretically.

The purpose of this paper is to obtain detailed thermal conductivity information on two different natural fibres; namely abaca and bamboo fibres. Using the simulation results reported by Liu et al. [12], the thermal conductivity of the solid part of natural fibres is estimated. The estimated data was slightly higher than reported data for natural fibres.

\section{Experimental methods}

\subsection{Materials}

Abaca fibres were supplied from Toho Tokusyu Pulp Co., Japan. The abaca fibre was mechanically extracted from the abaca plant in the Philippines and no surface treatment was used. The average sizes of the abaca fibre were a length of about $1.4 \mathrm{~m}$ and diameter of about $200 \mu \mathrm{m}$. Bamboo fibres were extracted by a steam explosion method as reported elsewhere $[11,14]$. The bamboo fibre was also used in as-received condition, namely without surface treatment. The colour of the bamboo fibre changed from light brown to dark brown after steam explosion treatments due to oxidation reaction of lignin in bamboo fibres. The average sizes of the bamboo fibre were a length of about $350 \mathrm{~mm}$ and diameter of about $200 \mu \mathrm{m}$. Low viscosity epoxy resin was used as a matrix (JER819, Mitsubishi Chemical Corporation, Japan). 


\subsection{Composites preparation method}

Natural fibre composites reinforced by unidirectional abaca fibres or bamboo fibres were fabricated by a resin transfer moulding technique as reported elsewhere [15]. The low viscosity epoxy resin was flowed into a specially designed transparent mould by using a rotary resin pump. The size of the sample obtained was $100 \times 100 \times 10 \mathrm{~mm}^{3}$ on average.

\subsection{Thermal conductivity measurement}

There are several methods to measure thermal conductivity of a composite plate. In this study, a steady-state method with reference plate was used [15]. After establishing a steady-state condition (as shown in fig. 1), the transverse thermal conductivity of a sample plate, $K$ can be calculated from the thermal conductivity of a reference plate $K_{r}$, the thickness of the sample $X_{s}$, that of the reference plates $X_{r}$, and also the differences between the temperatures of the sample and reference plates, $\Delta T_{s}$ and $\Delta T_{r}$ as follows:

$$
K=K_{r} \cdot \frac{X_{s}}{X_{r}} \cdot \frac{\Delta T_{r}}{\Delta T_{s}},
$$

where the temperature differences $\Delta T_{s}$ and $\Delta T_{r}$ are defined as follows:

$$
\Delta T_{s}=T_{1}-T_{2},
$$

and

$$
\Delta T_{r}=T_{2}-T_{3}
$$

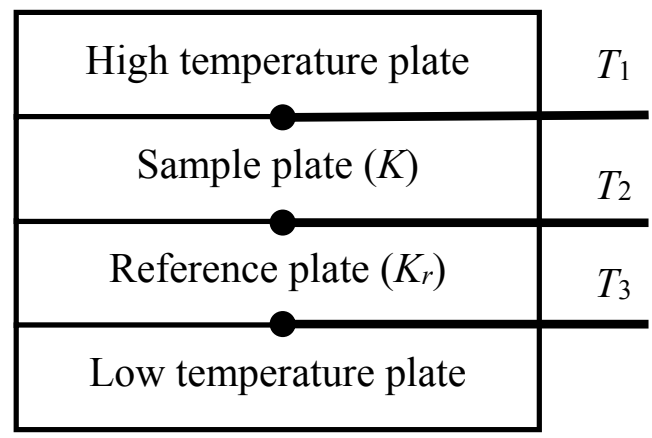

Figure 1: $\quad$ Schematic illustration of the steady-state method [15].

\subsection{Theoretical calculation of thermal conductivity using unit cell model}

The two-dimensional square arrayed pipe filament (SAPF) unit cell model [12] was applied to calculate the transverse thermal conductivity of the unidirectional natural fibre composites (fig. 2). The validity of this model, which is based on thermal-electrical analogies, was already provided by Liu et al. $[12,13]$. The most important factors affecting the transverse thermal conductivity are the lumen size $\left(\alpha=r_{L} / r_{f}\right)$, thermal conductivity ratio $\left(\beta=K_{f} / K_{m}\right)$ and fibre 
volume fraction $\left(V_{f}\right)$; where $r_{L}$ and $r_{f}$ are the radii of lumen and fibre, respectively, $K_{f}$ and $K_{m}$ are thermal conductivities of fibre solid part and matrix, respectively.
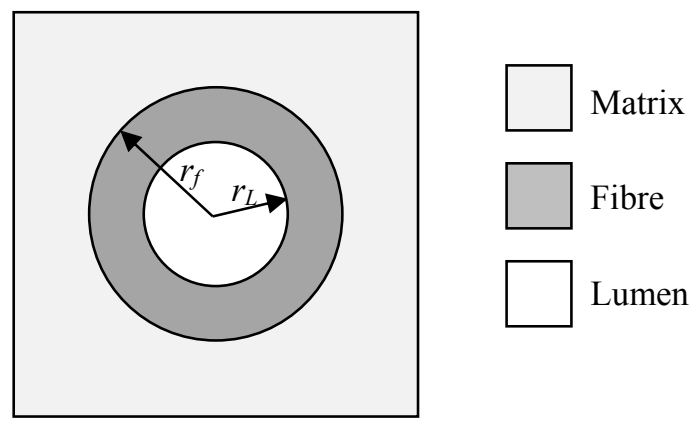

Figure 2: Schematic diagram of a two-dimensional SAPF unit cell model [12].

\section{Results and discussion}

The measured thermal conductivity data for the two composites reinforced by abaca and bamboo fibres are listed in table 1. In the case of bamboo fibrereinforced composites, the thermal conductivity increases with increasing fibre volume content, on the other hand that of abaca fibre-reinforced composites decreases showing an opposite dependence. The reason for this irregular dependence originates from the air filled in the lumens in the abaca fibres [13].

Table 1: Measured thermal conductivity data.

Abaca fibre composites

Bamboo fibre composites

\begin{tabular}{|c|c|c|c|}
\hline$V_{f}(\%)$ & $K(\mathrm{~W} / \mathrm{mK})$ & $V_{f}(\%)$ & $K(\mathrm{~W} / \mathrm{mK})$ \\
\hline 0.0 & 0.298 & 0.0 & 0.298 \\
\hline 13.4 & 0.292 & 7.0 & 0.307 \\
\hline 24.9 & 0.273 & 14.4 & 0.309 \\
\hline- & - & 22.42 & 0.317 \\
\hline
\end{tabular}

Fig. 3 shows the relationship between thermal conductivity and fibre volume content as a function of $\alpha$ [12]. It should be noted that the dependency on fibre content depends strongly on the lumen size, namely the value of $\alpha$. Even when $\beta>1$, decreasing dependence is obtained for the composites reinforced natural fibre with large lumen; i.e. large $\alpha$.

From a photomicrograph of abaca and bamboo fibres [15], the $\alpha$ values for abaca and bamboo fibres were found approximately 0.7 and 0.3 , respectively. From fig. 3, a graph can be drawn (fig. 4) showing the relationship between thermal conductivity ratio, $K / K_{m}$ and $\beta$. It can be seen that the thermal conductivity of the composites, $K$ increases with increasing $\beta$, and that this $K$ value becomes larger in the case of smaller $\alpha$. 

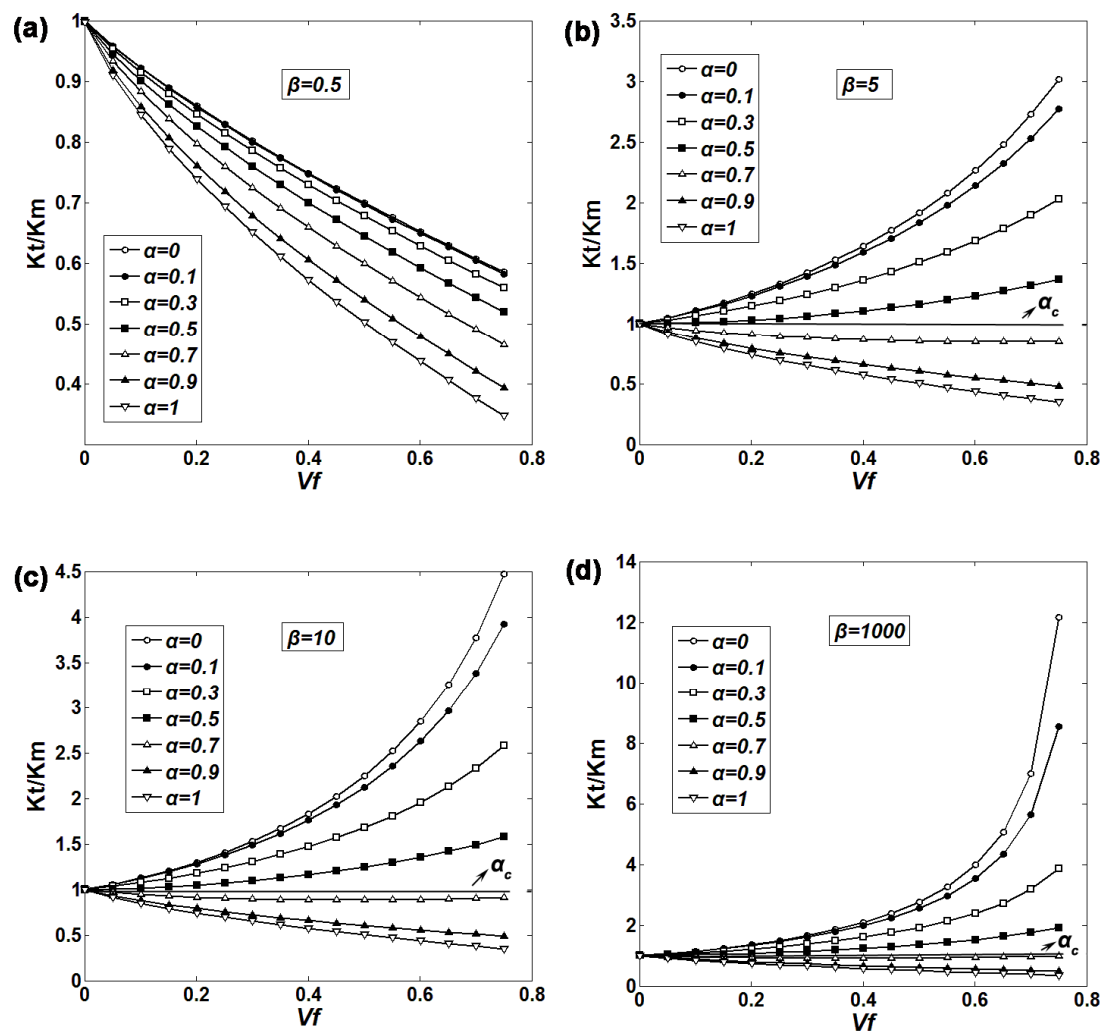

Figure 3: Calculated thermal conductivity from SAPF unit cell model [12].

As shown in table 1 , the thermal conductivity values for the composites reinforced with abaca and bamboo fibres, $K_{\exp }$, at a fibre volume fraction of 0.4 are calculated to be $0.256 \mathrm{~W} / \mathrm{mK}$ and $0.317 \mathrm{~W} / \mathrm{mK}$, respectively. The thermal conductivity of epoxy resin used as matrix was $0.298 \mathrm{~W} / \mathrm{mK}$ [12]. Thus, the $K_{\text {exp }} / K_{m}$ values for abaca and bamboo fibre-composites become 0.859 and 1.064 , respectively. From fig. 3 , the $\beta$ values for the composites reinforced with abaca and bamboo fibres are estimated to be 6.0 and 3.3, respectively, and the corresponding thermal conductivity for the solid part of abaca and bamboo fibres are $1.788 \mathrm{~W} / \mathrm{mK}$ and $0.983 \mathrm{~W} / \mathrm{mK}$, respectively. These values are higher than the reported value for cotton, that is, $0.54 \mathrm{~W} / \mathrm{mK}$, because this is the overall value for the cotton fibre with lumen. However, Shimazaki et al. [16] reported that the cellulose nanofibre composites have high thermal conductivity values and show qualitatively the same dependence. 


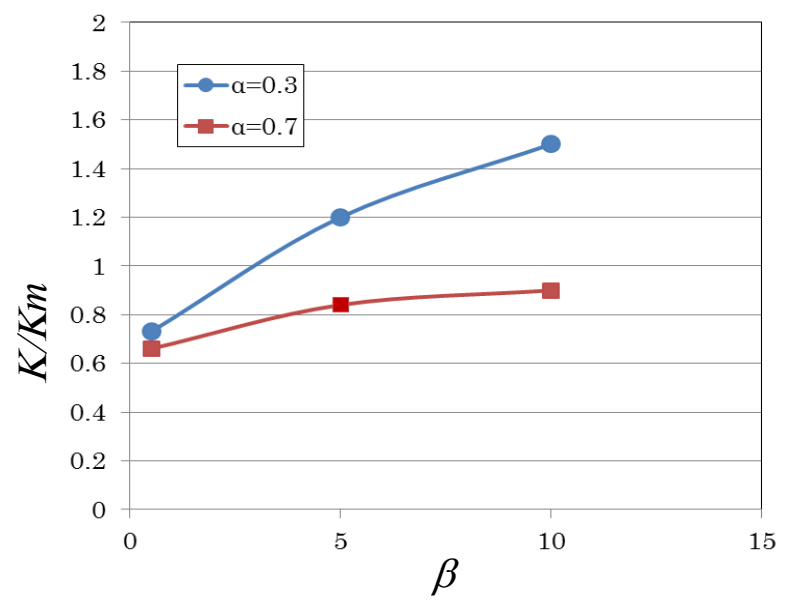

Figure 4: Relationship between thermal conductivity ratio, $K / K_{\mathrm{m}}$ and $\beta$.

\section{Conclusions}

In summary, the thermal conductivity of solid part of abaca fibre and bamboo fibre was evaluated from experimental measurements and theoretical calculations. It was found that the thermal conductivity for the solid part of abaca fibre and that of bamboo fibre are $1.788 \mathrm{~W} / \mathrm{mK}$ and $0.983 \mathrm{~W} / \mathrm{mK}$, respectively.

\section{Acknowledgement}

This work was partially supported by Japan Society for the Promotion of Science (JSPS) KAKENHI Grant Number 25289243.

\section{References}

[1] Netravali, A.N. \& Chabba, S., Composites get greener. Materials Today, 6(4), pp. 22-29, 2003.

[2] Omrani, A., Simon, L.C. \& Rostami, A.A., Influences of cellulose nanofiber on the epoxy network formation. Materials Science and Engineering A, 490(1-2), pp. 131-137, 2008.

[3] Wambua, P., Ivens, J. \& Verpoest, I., Natural fibres: can they replace glass in fibre reinforced plastics? Composites Science and Technology, 63(9), pp. 1259-1264, 2003.

[4] Wollerdorfer, M. \& Bader, H., Influence of natural fibres on the mechanical properties of biodegradable polymers. Industrial Crops and Products, 8(2), pp. 105-112, 1998.

[5] Luo, S. \& Netravali, A.N., Interfacial and mechanical properties of environment-friendly "green" composites made from pineapple fibers and 
poly(hydroxybutyrate-co-valerate) resin. Journal of Materials Science, 34(15), pp. 3709-3719, 1999.

[6] Luo, S. \& Netravali, A.N., Mechanical and thermal properties of environment-friendly green composites made from pineapple leaf fibers and poly(hydroxybutyrate-co-valerate) resin. Polymer Composites, 20(3), pp. 367-378, 1999.

[7] Lodha, P. \& Netravali, A.N., Characterization of interfacial and mechanical properties of "green" composites with soy protein isolate and ramie fiber. Journal of Materials Science, 37(17), pp. 3657-3665, 2002.

[8] Mohanty, A.K., Misra, M. \& Hinrichsen, G., Biofibres, biodegradable polymers and biocomposites: An overview. Macromolecular Materials and Engineering, 276/277(1), pp. 1-24, 2000.

[9] Mueller, D.H. \& Krobjilowski, A., New discovery in the properties of composites reinforced with natural fibers. Journal of Industrial Textiles, 33(2), pp. 111-130, 2003.

[10] Nakagaito, A.N. \& Yano, Y., Novel high-strength biocomposites based on microfibrillated cellulose having nano-order-unit web-like network structure. Applied Physics A, 80(1), pp. 155-159, 2005.

[11] Takagi, H., Kako, S., Kusano, K. \& Ousaka, A., Thermal conductivity of PLA-bamboo fiber composites. Advanced Composite Materials, 16(4), pp. 377-384, 2007.

[12] Liu, K., Takagi, H., Osugi, R. \& Yang, Z., Effect of lumen size on the effective transverse thermal conductivity of unidirectional natural fiber composites. Composites Science and Technology, 72(5), pp. 633-639, 2012.

[13] Liu, K., Takagi, H., Osugi, R. \& Yang, Z., Evaluation of transverse thermal conductivity of Manila hemp fiber in solid region using theoretical method and finite element method. Materials and Design, 32(8-9), pp. 4586-4589, 2011.

[14] Takagi, H. \& Ichihara Y., Effect of fiber length on mechanical properties of "green" composites using a starch-based resin and short bamboo fibers. JSME International Journal, Series A, 47(4), pp. 551-555, 2004.

[15] Takagi, H., Liu, K., Osugi, R., Nakagaito, A.N. \& Yang, Z., Heat barrier properties of green composites. Journal of Biobased Materials and Bioenergy, 6(4), pp. 470-474, 2012.

[16] Shimazaki, Y., Miyazaki, Y., Takezawa, Y., Nogi, M., Abe, K., Ifuku, S. \& Yano, H., Excellent thermal conductivity of transparent cellulose nanofiber/epoxy resin nanocomposites. Biomacromolecules, 8(9), pp. 2976-2978, 2007. 